\title{
A randomised pilot Phase $\|$ study of doxorubicin and cyclophosphamide (AC) or epirubicin and cyclophosphamide (EC) given 2 weekly with pegfilgrastim (accelerated) vs 3 weekly (standard) for women with early breast cancer
}

\author{
RL Jones', G Walsh', S Ashley', S Chua', R Agarwal', M O'Brien', S Johnston ',2 and IE Smith",I,2 \\ 'Breast Unit, Royal Marsden NHS Trust, Fulham Road, London SW3 6JJ, UK; ${ }^{2}$ Institute of Cancer Research, Fulham Road, London, UK
}

\begin{abstract}
Accelerated (dose-dense) chemotherapy, in which the frequency of administration is increased without changing total dose or duration, may increase the efficacy of cancer chemotherapy. We performed a randomised Phase II study to assess the safety and relative toxicity of AC (doxorubicin; cyclophosphamide) vs E(epirubicin)C given by conventional or accelerated schedules as neoadjuvant or adjuvant chemotherapy for early breast cancer. Furthermore, the relative toxicity of doxorubicin and epirubicin remains uncertain. Patients were randomised to one of four arms; four courses of standard 3 weekly cyclophosphamide 600 mg $\mathrm{m}^{-2}$ in combination with doxorubicin $60 \mathrm{mg} \mathrm{m}^{-2}$ (AC) vs epirubicin $90 \mathrm{mg} \mathrm{m}^{-2}$ (EC) 3 weekly vs the same regimens administered every 2 weeks with pegfilgrastim (G-CSF). A total of 126 patients were treated, 42 with standard AC, 42 with accelerated AC, 19 with standard EC and 23 with accelerated EC. Significantly more grade 3/4 day one neutropenia was seen with standard (6/6I, 10\%) compared to accelerated $(0 / 65$,$) regimens (P=0.01)$. A trend towards more neutropenic sepsis was seen in the combined standard and accelerated $A C$ arms (I2/84, I4\%) compared to the combined EC arms (1/42, 2\%), $P=0.06$. Falls in left ventricular ejection fraction were not increased with accelerated treatment. Accelerated AC and EC with pegfilgrastim are safe and feasible regimens in the treatment of early breast cancer with less neutropenia than conventional 3 weekly schedules.
\end{abstract} British Journal of Cancer (2009) 100, 305 - 310. doi:10.1038/sj.bjc.6604862 www.bjcancer.com (c) 2009 Cancer Research UK

Keywords: early breast cancer; doxorubicin; epirubicin; accelerated/dose-dense chemotherapy

Adjuvant anthracycline chemotherapy results in a significant survival benefit in women with moderate to high-risk early breast cancer (Early Breast Cancer Trialists' Collaborative Group, 2005). A large randomised trial has demonstrated four cycles of adjuvant doxorubicin and cyclophosphamide $(\mathrm{AC})$ to be as effective as 6 cycles of CMF (cyclophosphamide, methotrexate and 5-FU) in women with node-positive disease (Fisher et al, 1990). Subsequently, AC has become widely used throughout the world. Adjuvant anthracycline-based schedules have frequently included epirubicin instead of doxorubicin, but no data exist directly comparing the efficacy and safety of these two anthracyclines in early breast cancer.

Taxanes given sequentially or concurrently with anthracyclines have resulted in a further small, but significant, improvement in disease-free and overall survival particularly in node-positive disease (Bria et al, 2006), but short duration anthracycline/ cyclophosphamide schedules are still widely used for moderate risk patients.

*Correspondence: Professor IE Smith; E-mail: ian.smith@rmh.nhs.uk Received 28 August 2008; revised 18 November 2008; accepted 4 December 2008
A randomised trial of 2005 women has demonstrated a significant survival benefit for women, with lymph node-positive breast cancer, treated with dose-dense ( 2 weekly) chemotherapy with granulocyte colony stimulating factor (G-CSF) support compared to conventional 3 weekly schedules (Citron et al, 2003).

Our study aimed to assess the safety profile including cardiac safety of short duration (4 courses) standard AC vs EC given 3 -weekly compared with accelerated 2-week schedules of these two regimens.

\section{PATIENTS AND METHODS}

\section{Patient selection}

Patients with early breast cancer, suitable for adjuvant chemotherapy, were recruited following Research Ethics Committee approval. Written informed consent was obtained before trial entry. Inclusion criteria were age less than 70 years; ECOG performance status $0-1$; adequate haematological, renal and hepatic function; normal left ventricular ejection fraction (LVEF), assessed using multigated acquisition (MUGA) scan or echocardiography. Further inclusion criteria for the adjuvant arms were complete excision of histological confirmed adenocarcinoma; axillary resection or 
sentinel node biopsy; lymph node negative disease or 1-3 involved nodes if postmenopausal. Those entered into the neoadjuvant arms were required to have palpable tumours $\geqslant 2 \mathrm{~cm}$.

\section{Patient assessment}

Initial assessment included history and physical examination, full blood count, routine biochemistry, hormone receptor status, chest X-ray, electrocardiogram and MUGA scan. For the neoadjuvant arms, bi-dimensional calliper tumour measurements were obtained before therapy and after each cycle as well as ultrasonography at baseline and following cycles 2 and 4 .

\section{Treatment}

Patients were randomly assigned to one of four arms:

Standard AC - four cycles of doxorubicin $60 \mathrm{mg} \mathrm{m}^{-2}$ and cyclophosphamide $600 \mathrm{mg} \mathrm{m}^{-2}$ on day 1 , every 21 days;

Accelerated AC - four cycles of doxorubicin $60 \mathrm{mg} \mathrm{m}^{-2}$ and cyclophosphamide $600 \mathrm{mg} \mathrm{m}^{-2}$ on day 1 , every 14 days with depot recombinant human G-CSF (pegfilgrastim) $6 \mathrm{mg}$ subcutaneous injection on day 2 (Neulasta; Amgen, Cambridge, UK);

Standard EC - four cycles of epirubicin $90 \mathrm{mg} \mathrm{m}^{-2}$ and cyclophosphamide $600 \mathrm{mg} \mathrm{m}^{-2}$ on day 1, every 21 days;

Accelerated EC - four cycles of epirubicin $90 \mathrm{mg} \mathrm{m}^{-2}$ and cyclophosphamide $600 \mathrm{mg} \mathrm{m}^{-2}$ on day 1 , every 14 days with pegfilgrastim on day 2 .

Neoadjuvant patients were only randomised into the AC arms, because epirubicin was not recognised as a standard neoadjuvant therapy at the time of designing this trial.

Adjuvant endocrine therapy for a minimum of 5 years was given to those with hormone receptor-positive disease. Adjuvant radiotherapy was administered according to local policy at standard dose and fractionation.

\section{Response and toxicity assessment}

Clinical response was assessed before each cycle of neoadjuvant chemotherapy using WHO criteria (Miller et al, 1981). A pathological complete response (pCR) was defined as complete disappearance of invasive cancer cells in breast and nodes on histological examination (Sataloff et al, 1995).

Toxicity for each cycle was recorded before the commencement of the following cycle and was evaluated using the National Cancer Institute Common Toxicity Criteria. Haematological toxicity was determined before each course (day 21 for standard and day 14 for accelerated regimens).

\section{End points}

The primary end point was the incidence of grade $3 / 4$ neutropenia on day 1 of each cycle. Secondary endpoints were to compare other toxicity including cardiotoxicity; compliance and feasibility; the percentage of intended dose given.

\section{Cardiotoxicity}

Anthracycline cardiotoxicity was not anticipated with the cumulative doses used, but a protocol specification was included to identify any patient with cardiac failure and exclude them from further anthracycline-based therapy. Assessment of LVEF was performed at baseline, completion of chemotherapy, 1 and 2 years after chemotherapy.

\section{Dose modifications}

Dose modifications were made for main toxicities as follows:
Myelosuppression Chemotherapy was delayed by weekly intervals (maximum 3 weeks for 3 weekly and 2 weeks for 2 weekly regimens) until the neutrophil count $\geqslant 1 \times 10^{9}$ per litre and platelet count $\geqslant 100 \times 10^{9}$ per litre.

Febrile neutropenia For standard arms, the dose of anthracycline and cyclophosphamide were reduced by $20 \%$ and G-CSF administered according to American Society of Clinical Oncology guidelines (Ozer et al, 2000). For accelerated arms, 20\% dose reduction of anthracycline and cyclophosphamide was made in subsequent cycles.

\section{Statistical methods}

To answer the trial aims, 82 evaluable patients were required to be randomised in the adjuvant arms. This component of the study was designed to have a $90 \%$ probability of detecting a $30 \%$ reduction in grade $3 / 4$ neutropenia from $40 \%$ (AC/EC) to $10 \%$ (accelerated AC/EC). Randomisation was performed independently through the Institute of Cancer Research Clinical Trials and Statistics Unit.

Patient demographics and tumour characteristics of the different arms were compared, separately for adjuvant and neoadjuvant patients, between the randomised groups to check for any imbalance. The Kruskal-Wallis test was used for continuous or ordered categorical variables. The $\chi^{2}$-test or Fisher's exact test was used for comparison of binary variables.

All comparisons were two sided and, despite multiple testing, differences are reported at the 0.05 level of significance.

Comparisons were made between all patients treated with $\mathrm{AC}$ regimens and all patients treated with EC regimens. Comparisons were also made between all patients treated with accelerated regimens and all patients treated with standard regimens.

\section{RESULTS}

A total of 128 patients were randomised, and 126 analysed. Two (2\%) were excluded; one withdrew consent and the other had bilirubin and transaminase levels $\geqslant 1.5$ upper limit of normal. The number randomised into each arm with their clinical and pathological characteristics is shown in Table 1. Median follow up is 23 months. Eight (6\%) patients have relapsed and three (2\%) have died. In 18 (14\%) patients, 28 serious adverse events were recorded; 14 patients in the standard and 11 patients in the accelerated AC arms, and 1 in the standard and 2 patients in the accelerated EC arms.

\section{Haematological toxicity}

The number of patients with grade $3 / 4$ haematological toxicity in each subgroup (ie standard AC, accelerated AC, standard EC and accelerated EC) is shown in Table 2.

Significantly worse day 1 , grade $3 / 4$ neutropenia was seen in the standard ( 6 out of $61,10 \%$ ) compared to the accelerated ( 0 out of 65) arms, $P=0.01$. There were seven episodes of neutropenic sepsis in the standard arms (11\%; all AC) and six (9\%) in the accelerated arms (five AC and one EC), $P=0.7$.

No significant difference in day 1 , grade $3 / 4$ neutropenia was observed between the combined 2 and 3 weekly AC arms ( 3 out of 84 patients, $4 \%$ ) and combined 2 and 3 weekly EC arms ( 3 out of $42,7 \%), P=0.4$. There were 12 (out of $84,14 \%$ ) cases of neutropenic sepsis in the AC compared with only one (out of 42 , $2 \%)$ in the EC arms, $P=0.06$.

No significant difference in day 1 grade $3 / 4$ haematological toxicity was observed between the standard AC and standard EC arms (Table 3). Similarly, no significant difference in day 1 grade $3 / 4$ haematological toxicity was observed between the accelerated $\mathrm{AC}$ and accelerated EC arms (Table 3). 
Table I Clinical characteristics of patients in the four randomised arms

\begin{tabular}{|c|c|c|c|c|}
\hline All Patients & $\begin{array}{c}\text { Standard AC } \\
N(\%)\end{array}$ & $\begin{array}{c}\text { Accelerated AC } \\
N(\%)\end{array}$ & $\begin{array}{c}\text { Standard EC } \\
N(\%)\end{array}$ & $\begin{array}{c}\text { Accelerated EC } \\
N(\%)\end{array}$ \\
\hline $\begin{array}{l}\text { Patients: } \\
\quad \text { Adjuvant } \\
\text { Neoadjuvant } \\
\text { Age: Median (Range) }\end{array}$ & $\begin{array}{l}\quad 42 \\
23(55) \\
19(45) \\
48(33-68)\end{array}$ & $\begin{array}{l}\quad 42 \\
19(45) \\
23(55) \\
50(28-67)\end{array}$ & $\begin{array}{c}19 \\
19(100) \\
50(35-68)\end{array}$ & $\begin{array}{c}23 \\
23(100) \\
56(31-66)\end{array}$ \\
\hline $\begin{array}{l}\text { Menopausal status: } \\
\text { Pre } \\
\text { Peri } \\
\text { Post } \\
\text { Hysterectomy }\end{array}$ & $\begin{aligned} 21 & (50) \\
1 & (2) \\
17 & (4 \mid) \\
3 & (7)\end{aligned}$ & $\begin{array}{r}18(43) \\
7(17) \\
12(29) \\
5(12)\end{array}$ & $\begin{array}{l}12(63) \\
0 \\
5(26) \\
2(11)\end{array}$ & $\begin{aligned} 7 & (37) \\
1 & (5) \\
12 & (63) \\
3 & (16)\end{aligned}$ \\
\hline 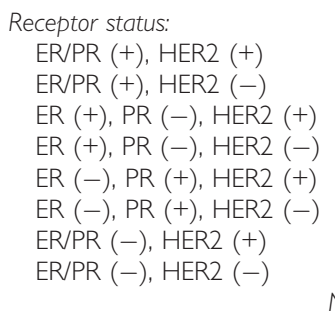 & $\begin{aligned} & 4(10) \\
& 13(31) \\
& 3(7) \\
& 5(12) \\
& 1(2) \\
& 1(2) \\
& 2(5) \\
& 11(26) \\
& N=2(5 \%), \text { ER (+on biopsy/-excision), PR/HER2 (-) }\end{aligned}$ & $\begin{array}{c}5(12) \\
20(48) \\
1(2) \\
3(7) \\
0 \\
0 \\
3(7) \\
10(24)\end{array}$ & $\begin{array}{c}2(11) \\
11(58) \\
0 \\
0 \\
0 \\
0 \\
3(16) \\
2(11) \\
N=I(5 \%), \operatorname{ER} / P R(-), \text { HER2 not known }\end{array}$ & $\begin{array}{c}3(13) \\
10(43) \\
0 \\
2(9) \\
1(4) \\
0 \\
0 \\
7(30)\end{array}$ \\
\hline $\begin{array}{l}\text { Pathology (pretreatment): } \\
\text { Infiltrating ductal } \\
\text { Infiltrating lobular } \\
\text { Other }\end{array}$ & $\begin{aligned} 36 & (86) \\
5 & (12) \\
1 & (2)\end{aligned}$ & $\begin{aligned} & 36(86) \\
& 5(12) \\
& 1(2)\end{aligned}$ & $\begin{array}{l}16(84) \\
2(11) \\
1(5)\end{array}$ & $\begin{array}{c}19(83) \\
4(17) \\
0\end{array}$ \\
\hline $\begin{array}{l}\text { Grade: } \\
\text { I } \\
\| \\
\text { III } \\
\text { Not known }\end{array}$ & $\begin{array}{c}0 \\
18(43) \\
24(57) \\
0\end{array}$ & $\begin{aligned} & 2(5) \\
21 & (50) \\
18 & (43) \\
1 & (2)\end{aligned}$ & $\begin{array}{l}1(5) \\
9(47) \\
9(47) \\
0\end{array}$ & $\begin{array}{c}1(4) \\
7(30) \\
15(65) \\
0\end{array}$ \\
\hline
\end{tabular}

\section{Treatment delivered}

Of 84 patients, 5 (6\%) treated with AC received only two courses of neoadjuvant chemotherapy because of failure to respond.

Three patients were treated with three cycles, one $(2 \%)$ on standard neoadjuvant AC discontinued therapy due to constipation and leg pain, and another on accelerated neoadjuvant AC developed a chest infection following three cycles. A patient on accelerated EC was treated for cellulitis and received three cycles. No significant difference in completing the intended course of chemotherapy was observed between the treatment arms (AC $v s$ EC, $P=0.6$ and standard $v s$ accelerated, $P=1.0$ ). The remaining 118 women completed four cycles.

\section{Treatment delays and additional growth factor support}

Of 84 patients, $5(6 \%)$ treated with AC were delayed for 1 week and $1(1 \%)$ for 2 weeks compared to 4 patients (out of $42,10 \%$ ) delayed for 1 week in the EC arms and 1 (2\%) for two weeks, $P=0.5$
(Table 2). Of 61 patients, 4 (7\%) in the standard arms were delayed for 1 week and 5 (out of $65,8 \%$ ) in the accelerated arms and a further 2 in the accelerated arms were delayed for 2 weeks, $P=0.5$.

Three patients underwent dose reduction, 2 out of $42(5 \%)$ in the standard AC arm and 1 out of $42(2 \%)$ in the accelerated AC arm.

Of 84 patients, $13(16 \%)$ in the $\mathrm{AC}$ arms required additional G-CSF compared to 4 (out of $42,10 \%$ ) in the EC arms, $P=0.4$ (Table 2). Of 61 patients, 13 (21\%) in the standard arms required G-CSF support compared to 4 out of $65(7 \%)$ in the accelerated arms who required additional G-CSF support, $P=0.02$.

\section{Cardiotoxicity}

No patient developed clinical cardiac failure. One patient in the standard AC arm had a fall in LVEF $\geqslant 10 \%$ to below $50 \%$, which subsequently recovered to $53 \%$. No significant difference in LVEF falls of $\geqslant 10 \%$ between the AC and EC arms was observed on completing treatment $(P=0.9), 1(P=0.5)$ and $2(P=1.0)$ years 
Table 2 Grade 3/4 haematological toxicity, treatment delays and additional G-CSF in the four randomised arms

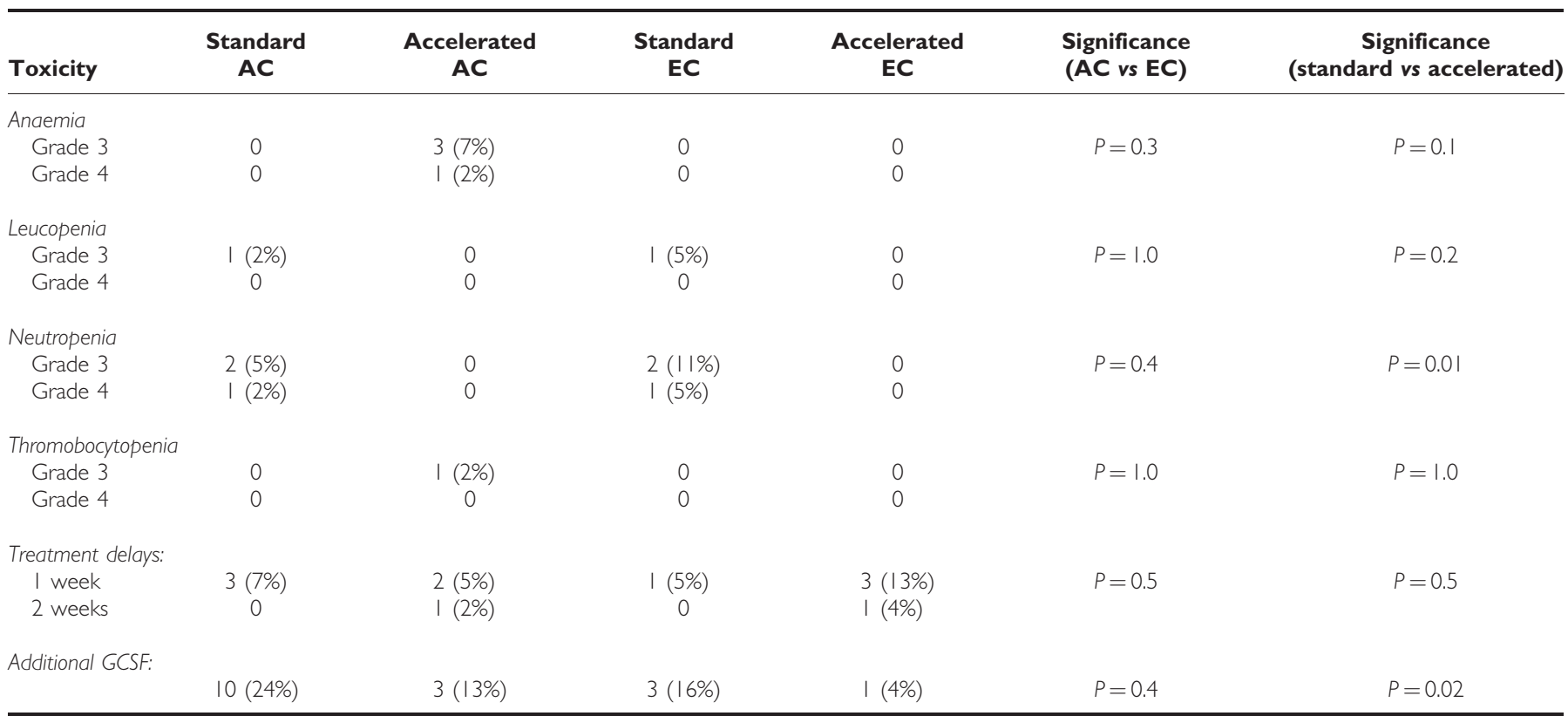

Table 3 Grade 3/4 haematological toxicity in the standard and accelerated $A C$ and $E C$ arms

\begin{tabular}{lcccc}
\hline & $\begin{array}{c}\text { Grade 3/4 } \\
\text { leucopenia }\end{array}$ & $\begin{array}{c}\text { Grade } \mathbf{3 / 4} \\
\text { neutropenia }\end{array}$ & $\begin{array}{c}\text { Grade 3/4 } \\
\text { anaemia }\end{array}$ & $\begin{array}{c}\text { Grade 3/4 } \\
\text { thrombocytopenia }\end{array}$ \\
\hline Standard AC & I (2.4\%) & $3(7.1 \%)$ & 0 & 0 \\
Standard EC & I (5.3\%) & $3(15.8 \%)$ & 0 & 0 \\
& $P=0.5$ & $P=0.4$ & $P=1.0$ & $P=1.0$ \\
Accelerated AC & 0 & 0 & $4(9.5 \%)$ & $\mid(2.4 \%)$ \\
Accelerated EC & 0 & 0 & 0 & 0 \\
& $P=1.0$ & $P=1.0$ & $P=0.3$ & $P=1.0$ \\
Standard AC & $\mid(2.4 \%)$ & $3(7.1 \%)$ & 0 & 0 \\
Accelerated AC & 0 & 0 & $4(9.5 \%)$ & $\mid(2.4 \%)$ \\
& $P=0.1$ & $P=0.1$ & $P=1.0$ & $P=1.0$ \\
Standard EC & $\mid(5.3 \%)$ & $3(15.8 \%)$ & 0 & 0 \\
Accelerated EC & 0 & 0 & 0 & 0 \\
& $P=0.5$ & $P=0.08$ & $P=0.1$ & $P=0.1$ \\
\hline
\end{tabular}

after therapy (Table 4). No significant difference in LVEF falls of $\geqslant 10 \%$ between the standard and accelerated arms was observed on completing treatment $(P=0.7)$, one $(P=0.8)$ and two $(P=0.8)$ years post therapy.

\section{Other toxicity}

Non-haematological toxicity is shown in Table 5.

No significant difference in grade $3 / 4$ stomatitis was observed between patients treated with both standard regimens, 3 out of 61 $(5 \%)$, and both accelerated regimens, 4 out of $65(6 \%), P=1.0$. There was a non-significant trend towards more grade $3 / 4$ stomatitis in patients treated with all AC regimens, 7 (out of 84 , $8 \%)$, compared to all EC regimens, 0 out of $42(P=0.09)$.

No significant difference in grade $3 / 4$ stomatitis was observed between the standard AC $(3 / 42,7.1 \%)$ and the standard EC $(0 / 19)$ arms, $P=0.5$. Similarly, no significant difference in grade $3 / 4$ stomatitis was observed between the accelerated AC (4/42, 9.5\%)
Table 4 Decrease in LVEF $\geqslant 10 \%$ on completion, I and 2 years after chemotherapy,

\begin{tabular}{lcccc}
\hline LVEF assessment & $\begin{array}{c}\text { Standard } \\
\text { AC }\end{array}$ & $\begin{array}{c}\text { Accelerated } \\
\text { AC }\end{array}$ & $\begin{array}{c}\text { Standard } \\
\text { EC }\end{array}$ & $\begin{array}{c}\text { Accelerated } \\
\text { EC }\end{array}$ \\
\hline End of therapy & $6(14 \%)$ & $3(7 \%)$ & $2(11 \%)$ & $2(9 \%)$ \\
I year after therapy & $7(17 \%)$ & $3(7 \%)$ & 0 & $3(13 \%)$ \\
2 years after therapy & $6(14 \%)$ & $3(7 \%)$ & $3(7 \%)$ & $1(4 \%)$ \\
Percentage with 2-year & $71 \%$ & $69 \%$ & $58 \%$ & $71 \%$ \\
MUGA scans & & & &
\end{tabular}

Comparison $\downarrow$ LVEF $\geqslant 10 \%$ between $A C$ and EC regimens. End of therapy, $P=0.9$ One year post therapy, $P=0.5$. Two years post therapy, $P=1.0$. Comparison $\downarrow$ LVEF $\geqslant 10 \%$ between standard and accelerated regimens. End of therapy, $P=0.7$. One year post therapy, $P=0.8$. Two years post therapy, $P=0.8$.

and accelerated EC $(0 / 23)$ arms, $P=0.3$. No significant difference in grade $3 / 4$ stomatitis was observed between the standard $(3 / 42$, $7.1 \%)$ and accelerated $(4 / 42,9.5 \%) \mathrm{AC}$ arms $(P=1.0)$ or between the standard (0/19) and accelerated $(0 / 23)$ EC arms.

No significant difference was observed in grade $3 / 4$ infection rate between those treated with standard, 8 out of $61(13 \%)$, and accelerated, 8 out of $65(12 \%)$, regimens $(P=1.0)$. Of 84 patients, $14(17 \%)$ treated with AC developed grade 3/4 infections, including neutropenic sepsis (see above), compared with 2 (out of $42,5 \%$ ) treated with EC, $P=0.09$.

A significant difference in grade $3 / 4$ infection was found between the standard AC $(8 / 42,19.0 \%)$ and standard EC $(0 / 19)$ arms, $P=0.05$. No significant difference in grade $3 / 4$ infection rate was observed between the accelerated AC $(6 / 42,14.3 \%)$ and accelerated EC $(2 / 23,8.7 \%)$ arms, $P=0.7$. Likewise, no significant difference in grade $3 / 4$ infection rate was seen between the standard AC $(8 / 42,19.0 \%)$ and accelerated AC $(6 / 42,14.3 \%)$ arms $(P=0.8)$ or between the standard EC $(0 / 19)$ and accelerated EC $(2 /$ $23,8.7 \%)$ arms $(P=0.5)$

No significant difference in other non-haematological toxicity was observed between the AC vs EC and standard vs accelerated arms. There were no reports of grade $3 / 4$ bone pain, and no patient stopped pegfilgrastim due to bone pain. 
Table 5 Grade 3/4 non-haematological toxicities in the four arms

\begin{tabular}{|c|c|c|c|c|}
\hline Toxicity & $\begin{array}{c}\text { Standard } \\
\text { AC }\end{array}$ & $\begin{array}{c}\text { Accelerated } \\
\text { AC }\end{array}$ & $\begin{array}{c}\text { Standard } \\
\text { EC }\end{array}$ & $\begin{array}{c}\text { Accelerated } \\
\text { EC }\end{array}$ \\
\hline \multicolumn{5}{|l|}{ Infection } \\
\hline Grade 3 & $6(14 \%)$ & $6(14 \%)$ & 0 & $2(9 \%)$ \\
\hline Grade 4 & $2(5 \%)$ & 0 & 0 & 0 \\
\hline \multicolumn{5}{|l|}{ Lethargy } \\
\hline Grade 3 & $3(7 \%)$ & $7(17 \%)$ & 0 & $2(9 \%)$ \\
\hline Grade 4 & 0 & 0 & 0 & 0 \\
\hline \multicolumn{5}{|c|}{ Nausea/vomiting } \\
\hline Grade 3 & $3(5 \%)$ & $2(5 \%)$ & 0 & 0 \\
\hline Grade 4 & 0 & 0 & 0 & 0 \\
\hline \multicolumn{5}{|l|}{ Stomatitis } \\
\hline Grade 3 & $3(7 \%)$ & $4(10 \%)$ & 0 & 0 \\
\hline Grade 4 & 0 & 0 & 0 & 0 \\
\hline \multicolumn{5}{|l|}{ Diarrhoea } \\
\hline Grade 3 & $2(5 \%)$ & 0 & | (5\%) & 0 \\
\hline Grade 4 & 0 & 0 & 0 & 0 \\
\hline \multicolumn{5}{|l|}{ Erythema } \\
\hline Grade 3 & I (2\%) & | (2\%) & 0 & 0 \\
\hline Grade 4 & 0 & 0 & 0 & 0 \\
\hline \multicolumn{5}{|l|}{ Constipation } \\
\hline Grade 3 & | (2\%) & I (2\%) & 0 & | (4\%) \\
\hline Grade 4 & 0 & 0 & 0 & 0 \\
\hline \multicolumn{5}{|l|}{ Bone pain } \\
\hline Grade 3 & 0 & 0 & 0 & 0 \\
\hline Grade 4 & 0 & 0 & 0 & 0 \\
\hline \multicolumn{5}{|l|}{ Nail changes } \\
\hline Grade 3 & I & 0 & 0 & 0 \\
\hline Grade 4 & 0 & 0 & 0 & 0 \\
\hline
\end{tabular}

There were no treatment related deaths and no reports of myelodysplastic syndrome or acute myeloid leukaemia.

\section{Clinical and pathological response rates in the neoadjuvant arms}

No significant difference in clinical complete and partial response was observed between the standard, 15 (79\%), and accelerated AC, $16(70 \%)$, arms $(P=0.6)$. No significant difference in pCR rate was observed between the standard, $2(11 \%)$, and accelerated AC, 3 $(13 \%)$, arms $(P=0.9)$.

\section{DISCUSSION}

This study has demonstrated that accelerated EC and AC given at 2 weekly intervals with pegfilgrastim support are at least as well tolerated as the same schedules given over standard 3-week intervals in early breast cancer, with fewer grade $3 / 4$ neutropenia. Citron et al (2003) compared standard 3 weekly and accelerated 2 weekly schedules of concurrent doxorubicin and cyclophosphamide followed by paclitaxel, or sequential doxorubicin, paclitaxel and cyclophosphamide. As in our study, they found that grade 4 neutropenia was more frequent in the standard 3 weekly schedules than in the accelerated regimens ( $33 \%$ vs $6 \%, P<0.0001)$.

Likewise in a Phase III randomised trial comparing 3 weekly FEC with the same regimen given every two weeks with G-CSF support, a higher incidence of leucopenia was observed in the 3 weekly schedule (45 vs 12\%, $P<0.001$; Venturini et al, 2005). In contrast, a higher incidence of any grade thrombocytopenia ( 8 vs $2 \%$ ) and bone pain (33 vs $4 \%$ ) was observed in the dosedense FEC regimen.

These other trials did not look at cardiotoxicity in detail and it was therefore reassuring for us to find no evidence of increased subclinical cardiotoxicity monitored by serial LVEF with the accelerated $v s$ standard approach in our study.

Our Phase II trial was not powered to detect differences in efficacy. Citron et al (2003) however showed a significant improvement in overall survival with dose-dense therapy (risk ratio $=0.69, P=0.013$ ), with 3 -year overall survival of $92 \%$ in the dose-dense arms and $90 \%$ in the 3 weekly arms.

In contrast, no survival difference was found between the standard and accelerated regimens in the Phase III trial comparing 3 weekly FEC with the same regimen given every 2 weeks with G-CSF support, with an actuarial 10-year survival of $80 \%$ in the accelerated arm compared with $78 \%$ in the standard arm $(P=0.35$; Venturini et al, 2005). However, this trial with 1214 patients had limited statistical power to answer this question.

This exploratory Phase II trial has shown that EC, with an epirubicin dose of $90 \mathrm{mg} \mathrm{m}^{-2}$ is at least as well tolerated as AC using a doxorubicin dose of $60 \mathrm{mg} \mathrm{m}^{-2}$. The trend towards higher incidence of neutropenic sepsis, grade $3 / 4$ stomatitis and grade 3 nausea/vomiting in the AC arms of our trial suggest that EC may be a better option and indicate the need for further comparison of the relative toxicity of doxorubicin and epirubicin. The key issue here concerns dose. A French adjuvant chemotherapy trial has shown that epirubicin $100 \mathrm{mg} \mathrm{m}^{-2}$ is more effective than $50 \mathrm{mg} \mathrm{m}^{-2}$ but also more toxic (French Adjuvant Study Group, 2001). The shape of the dose response curve for epirubicin between 50 and $100 \mathrm{mg} \mathrm{m}^{-2}$ and the optimal dose remains a topic of controversy, but $90 \mathrm{mg} \mathrm{m}^{-2}$ is also widely used and is unlikely to be significantly less effective than $100 \mathrm{mg} \mathrm{m}^{-2}$. Our observations reinforce the need for further dose response data on the efficacy of epirubicin. Interest has also focused on the use of docetaxel in combination with cyclophosphamide (Jones et al, 2006).

In conclusion, $\mathrm{E}$ (epirubicin dose of $90 \mathrm{mg} \mathrm{m}^{-2}$ ) C is at least as well tolerated as A(doxorubicin $60 \mathrm{mg} \mathrm{m}^{-2}$ ) C and accelerated AC or EC given 2 weekly with pegfilgrastim support is at least as safe and as well tolerated as when given conventionally at 3-week intervals.

\section{ACKNOWLEDGEMENTS}

We thank the Institute of Cancer Research Clinical Trials and Research Unit for providing a randomisation service and to Amgen (UK) for supplying pegfilgrastim.

\section{REFERENCES}

Bria E, Nistico C, Cuppone F, Carlini P, Ciccarese M, Milella M, Natoli G, Terzoli E, Cognetti F, Giannarelli D (2006) Benefit of taxanes as adjuvant chemotherapy for early breast cancer: pooled analysis of 15,500 patients. Cancer 106: $2337-2344$

Citron ML, Berry DA, Cirrincione C, Hudis C, Winer EP, Gradishar WJ, Davidson NE, Martino S, Livingston R, Ingle JN, Perez EA, Carpenter J,

Hurd D, Holland JF, Smith BL, Sartor CI, Leung EH, Abrams J, Schilsky RL, Muss HB, Norton L (2003) Randomized trial of dose-dense versus conventionally scheduled and sequential versus concurrent combination chemotherapy as postoperative adjuvant treatment of node-positive primary breast cancer: first report of Intergroup Trial C9741/Cancer and Leukemia Group B Trial 9741. J Clin Oncol 21: 1431-1439 
Early Breast Cancer Trialists' Collaborative Group (EBCTCG) (2005) Effects of chemotherapy and hormonal therapy for early breast cancer on recurrence and 15- year survival: an overview of the randomised trials. Lancet 365: $1687-1717$

Fisher B, Brown AM, Dimitrov NV, Poisson R, Redmond C, Margolese RG Bowman D, Wolmark N, Wickerham DL, Kardinal CG et al (1990) Two months of doxorubicin-cyclophosphamide with and without interva reinduction therapy compared with 6 months of cyclophosphamide, methotrexate, and fluorouracil in positive-node breast cancer patients with tamoxifen-nonresponsive tumors: results from the National Surgical Adjuvant Breast and Bowel Project B-15. J Clin Oncol 8: 1483-1496

French Adjuvant Study Group (2001) Benefit of a high-dose epirubicin regimen in adjuvant chemotherapy for node-positive breast cancer patients with poor prognostic factors: 5-year follow-up results of French Adjuvant Study Group 05 randomized trial. J Clin Oncol 19: 602-611

Jones SE, Savin MA, Holmes FA, O'Shaughnessy JA, Blum JL, Vukelja S, McIntyre KJ, Pippen JE, Bordelon JH, Kirby R, Sandbach J, Hyman WJ, Khandelwal P, Negron AG, Richards DA, Anthony SP, Mennel RG, Boehm KA, Meyer WG, Asmar L (2006) Phase III trial comparing doxorubicin plus cyclophosphamide with docetaxel plus cyclophos- phamide as adjuvant therapy for operable breast cancer. J Clin Oncol 24: $5381-5387$

Miller AB, Hoogstraten B, Staquet M, Winkler A (1981) Reporting results of cancer treatment. Cancer 47: $207-214$

Ozer H, Armitage JO, Bennett CL, Crawford J, Demetri GD, Pizzo PA, Schiffer CA, Smith TJ, Somlo G, Wade JC, Wade III JL, Winn RJ, Wozniak AJ, Somerfield MR, American Society of Clinical Oncology (2000) 2000 update of recommendations for the use of hematopoietic colony-stimulating factors: evidence-based, clinical practice guidelines. American Society of Clinical Oncology Growth Factors Expert Panel J Clin Oncol 18: $3558-3585$

Sataloff DM, Mason BA, Prestipino AJ, Seinige UL, Lieber CP, Baloch Z (1995) Pathologic response to induction chemotherapy in locally advanced carcinoma of the breast: a determinant of outcome. J Am Coll Surg 180: $297-306$

Venturini M, Del Mastro L, Aitini E, Baldini E, Caroti C, Contu A, Testore F, Brema F, Pronzato P, Cavazzini G, Sertoli MR, Canavese G, Rosso R, Bruzzi P (2005) Dose-dense adjuvant chemotherapy in early breast cancer patients: results from a randomized trial. J Natl Cancer Inst 97: $1724-1733$ 